\title{
Influência da autoestima e relação orientador- orientando nos sintomas da Síndrome de Burnout: evidências da pós-graduação stricto sensu em Contabilidade no contexto brasileiro
}

\author{
Vinicius Abilio Martins \\ https://orcid.org/0000-0002-5668-5518 | E-mail: viniciusabilio@gmail.com \\ Sheila da Silva \\ https://orcid.org/0000-0002-6492-9535 | E-mail: sheilasilva1917@hotmail.com \\ Igor Pereira da Luz \\ https://orcid.org/0000-0002-3932-3611 ｜ E-mail: i.pereiradaluz@gmail.com
}

\section{Resumo}

Objetivo:O presente trabalho teve por objetivo analisar a influência da autoestima e a relação orientadororientando nos sintomas da Síndrome de Burnout em estudantes de pós-graduação stricto sensu em Contabilidade no Brasil.

Método:O estudo é descritivo, de abordagem quantitativa, caracterizado como pesquisa de levantamento, tipo survey. Foram utilizadas a Escala de Autoestima de Rosenberg (1965), a escala MBI-HSS para a análise da existência de traços da Síndrome de Burnout e a escala para avaliar as percepções de boa relação orientador-orientando desenvolvida por Silva e Vieira (2015). A população selecionada foram os acadêmicos (mestrandos e doutorandos) de pós-graduação stricto sensu na área de Ciências Contábeis no Brasil e a amostra final é composta de 141 respostas válidas. Para a análise de dados, foi utilizada a análise descritiva, análise fatorial e para o teste de hipóteses a Modelagem de Equações Estruturais.

Resultados: Os resultados apontam para uma influência negativa da percepção de autoestima nos sintomas da Síndrome de Burnout.Aponta-se, com isso, para a importância da autoestima na condução das adversidades apresentadas pelas demandas da pós-graduação. Aponta-se, também, para uma influência negativa e significativa da acessibilidade do orientador no sentimento de baixa eficácia e a boa relação do orientador com o sentimento de exaustão. Infere-se a importância da relação com o orientador para o não desenvolvimento de sintomas da Síndrome de Burnout.

Contribuições: Como contribuições, o estudo apresenta um panorama sobre a percepção dos acadêmicos acerca da sua autoestima, a relação com o orientador e os sintomas da Síndrome de Burnout, temas com pouca evidência nos programas de pós-graduação em Contabilidade nacional. No mais, os resultados apontam para a importância de trabalhar a autoestima, no contexto da pós-graduação para evitar os sentimentos de baixa eficácia, exaustão e descrença.

Palavras-chave: Síndrome de Burnout. Autoestima. Relação orientador-orientando. Pós-graduação. Contabilidade. 


\section{Introdução}

As universidades possuem um papel imprescindível diante do desenvolvimento humano, cuja natureza é marcada pelo duplo papel de formação das novas gerações e produção do conhecimento (Franco, Longhi\& Ramos, 2009). Para o indivíduo que ingressa na pós-graduação, o processo de aprendizagem pode ser significativo na formação acadêmica e pode possibilitar a compreensão da aprendizagem a partir de suas vivências (Lima \& Silva, 2017).

O permanente exercício da crítica, que se sustenta na pesquisa (Bispo \& Santos Junior, 2014) em que ocorre a descoberta como uma instituição social, no qual o conhecimento é guiado pela própria necessidade e lógica (Pimenta \& Anastasiou, 2002), é habitat propício para desencadear a força estratégica da produção da pesquisa científica (Franco et al., 2009). Tendo em vista que o principal produto da pósgraduação stricto sensu é a pesquisa, o volume de pesquisas e a qualidade delas se tornaram um dos principais indicadores de avaliação do desempenho, tanto de programas de pós-graduação quanto de docentes e discentes (Cadez, Dimovski\&Groff (2017). Como consequência, os acadêmicos sofrem com a necessidade de produzir e com a cobrança dos cursos, podendo este ser um fator estressante para os estudantes (Voltarelli, 2002). Estudos apontam que o estudante, na pós-graduação, está em constante pressão, tendo que conciliar o papel de pesquisador com suas atividades particulares, além de lidar com prazos (Duque, Brondani\& Luna, 2005; Souza et al, 2010).

Ao considerar que a atividade de pesquisa é de certa forma desgastante, aliada à pressão exercida pelos programas de pós-graduação e orientadores, é possível inferir que o ambiente em que os acadêmicos de pós-graduação se encontram seja propício ao desenvolvimento dos sintomas da Síndrome de Burnout (Benevides-Pereira, 2002; Codo, 2002; López, Boluda\&Sanden, 2012). Todavia, ainda são poucas as evidências da literatura sobre os sintomas da Síndrome de Burnout com o contexto da pós-graduação (Hish, Nagy, Fang, Kelley, Nicchitta, Dzirasa \& Rosenthal, 2019).

A Síndrome de Burnout possui um caráter depressivo, no qual o indivíduo acometido por este distúrbio se sente desmotivado, não possui mais energia, encontra-se em um estado de exaustão física e emocional, e não possui mais condição ou motivação para desempenhar suas atividades. O desenvolvimento da Síndrome de Burnout é condicionado por variáveis demográficas, variáveis relacionadas à personalidade, formas de lidar com dificuldades e fatores organizacionais/profissionais (Kupcewicz\&Jozwik, 2020).

Outro aspecto que se relaciona com possíveis desgastes do acadêmico na pós-graduação é a sua relação com o orientador. O aumento dos cursos de pós-graduação agregou, entre as diversas atividades de um docente, o papel de orientador (Leite Filho \& Martins, 2006). Esta é considerada uma atividade delicada, pois, além de um auxílio para encontrar um tema, exige a necessidade de pesquisa, produtividade e relações que vão além de orientando/orientador, relações de respeito e admiração (Brown \& Adkins, 1998; Silva \& Vieira, 2015). Em alguns casos, o orientador não possui a capacidade ou maturidade necessária, ou mesmo um bom relacionamento interpessoal, influenciando a relação com o orientando (Goldberg, 1980; Silva \& Vieira, 2015).

A autoestima também desempenha papel considerável como preditora de resultados favoráveis, tendo implicações em áreas como sucesso ocupacional, relacionamentos interpessoais e desempenho acadêmico (Trzesniewski, Donnellan \& Robins, 2003). Além disso, a literatura aponta existir relacionamento entre autoestima e os sintomas da Síndrome de Burnout (Masclet\&Mineure, 1999).

No entanto, pesquisas que relacionam a síndrome de Burnout em estudantes de pós-graduação ainda não conquistaram consolidação teórica (Silva \& Vieira, 2015), inclusa a discussão do relacionamento entre autoestima e Síndrome de Burnout. Desta forma, emerge a seguinte questão: Qual a influência da autoestima e relação orientador-orientando nos sintomas da Síndrome de Burnout em estudantes de pós-graduação stricto sensu em Contabilidade no Brasil? Para responder à questão levantada, a presente pesquisa tem por objetivo analisar a influência da autoestima e a relação orientador-orientando nos sintomas da Síndrome de Burnout em estudantes de pós-graduação stricto sensu em Contabilidade no Brasil. 
Como justificativa desta pesquisa, tem-se a possibilidade de contribuir de forma teórica para o entendimento entre a relação orientador-orientando e a Síndrome de Burnout na área de ensino contábil. Muitos modelos e teorias foram apresentados para descrever a complexa construção do estresse ao longo de décadas, inclusive os sintomas da Síndrome de Burnout (Hish, et al., 2019). No entanto, a aplicação da relação entre Burnout, a relação orientador-orientando e a autoestima é identificada como lacuna que carece de pesquisa. Ainda, de forma prática, a contribuição se dá para os programas de pós-graduação, podendo visualizar medidas que prezem pelo bem-estar e pela saúde dos estudantes, bem como por uma relação saudável entre orientadores e orientandos.

\section{Referencial Teórico}

\subsection{Síndrome de Burnout, autoestima e relação orientador-orientando}

Burnout é um construto que descreve o estado psicológico resultante de estratégias ineficazes para lidar com o estresse duradouro no trabalho. No entanto, mesmo após mais de 25 anos de trabalho clínico e científico, ainda não existe uma definição geral de Burnout (Ekstedt \& Fagerberg, 2005). O termo Burnout faz referência a um estado mental de exaustão, semelhante ao de um incêndio que se extingue ou uma bateria que se esgota (López et al, 2012). A expressão é utilizada como definição para o estado daquela pessoa que chegou ao limite e, por falta de energia, não tem mais condições de desempenho físico e mental (Benevides-Pereira, 2002).

Em 1969, este termo já havia sido utilizado, com o intuito de propor "uma nova estrutura organizacional, a fim de conter o fenômeno psicológico que acomete trabalhadores assistenciais" (Benevides-Pereira, 2002, p. 21). Porém, os estudos referentes à Síndrome de Burnout tiveram maior destaque a partir dos artigos de Freundenberger (1975).

É característico do indivíduo acometido pela Síndrome de Burnout sentir falta de energia, sendo esta uma resposta ao estresse sofrido no ambiente de trabalho (Zuluaga\&Moreno, 2012). Também poderá apresentar exaustão emocional, despersonalização e baixa realização profissional (Fuente, San Luis, Lozano, Vargas, García\&Emilia, 2014).

A síndrome tem um desenvolvimento gradual e cumulativo. Apresenta-se em diferentes graus e são notáveis os seguintes sintomas: irritação, inquietação, frustração e esgotamento (Mallmann, Palazzo, Carlotto\&de Castro Aerts, 2009). Os sintomas podem evoluir de uma apresentação esporádica para permanente e contribuir para o surgimento de doenças e sintomas físicos ocasionados pelo mal-estar.

É «uma síndrome por meio da qual o trabalhador perde o sentido de sua relação com o trabalho [...] afeta, principalmente, profissionais das áreas de educação e saúde quando em contato direto com seus usuários" (Codo, 2002, p. 238). Burnout é a manifestação prolongada de estressores crônicos sejam eles emocionais ou interpessoais (Maslach 1976; Schuster, Dias \& Battistella, 2015). A síndrome pode ser definida em três dimensões, que se encontram na Tabela 1:

Tabela 1

Dimensões da Síndrome de Burnout

\begin{tabular}{ll}
\hline \multicolumn{1}{c}{ Dimensões } & \multicolumn{1}{c}{ Conceito } \\
\hline Eficácia & $\begin{array}{l}\text { Refere-se às expectativas do indivíduo quanto ao trabalho, incluindo as expectativas de } \\
\text { eficácia continuada no trabalho. }\end{array}$ \\
\hline Exaustão & $\begin{array}{l}\text { Está associada a sentimentos de excesso de esforço, cansaço extremo, fadiga, que advêm de } \\
\text { um longo envolvimento com atividades exigentes. }\end{array}$ \\
\hline Descrença & $\begin{array}{l}\text { O indivíduo reflete uma atitude indiferente e distante em relação ao trabalho não possui } \\
\text { entusiasmo, redução da energia empregada na realização das atividades, diminuição da } \\
\text { eficácia profissional. }\end{array}$ \\
\hline
\end{tabular}

Fonte: Schuster et al. (2015) 
As características que podem levar ao desenvolvimento da Síndrome de Burnout são diversas. Originalmente, acreditava-se que ela atingia apenas indivíduos que desempenhavam funções com gestão de pessoas, como: saúde, educação, assistência social, entre outros (Maslach, 1976; Silva \& Vieira, 2015). Porém, pesquisas já evidenciam a ocorrência da síndrome em relacionamentos entre pais e filhos e entre estudantes (Maslach 1976; Silva \& Vieira, 2015). Os estudantes universitários frequentemente sofrem pressões relacionadas a requisitos acadêmicos, o que os tornapropensos à exaustão emocional ( $\mathrm{Li}$ et al, 2018).

A autoestima tem sido objeto de estudo sob o enfoque de trabalhadores, estudantes e acadêmicos. Identificou-se que a presença de autoestima mais elevada apresenta influência na presença de níveis mais baixos dos sintomas da Síndrome de Burnout (Leroy-Frémont; Desrumaux\&Moundjiegout, 2014; Kang;Twigg\&Hertzman, 2010). Assim, a baixa autoestima pode ser considerada preditora de Burnout (Johnson et al, 2020).

Outras pesquisas apontam a relação da autoestima com outros aspectos relacionados com estudantes. A autoestima durante os estudos universitários pode apresentar impacto sobre as características da carreira profissional de estudantes universitários, dentre elas ter um alto salário, relatar um alto nível de engajamento e satisfação no trabalho e um baixo nível de esgotamento. Por outro lado, a baixa autoestima durante período acadêmico previa desemprego, sentimentos de exaustão, cinismo e realização reduzida no trabalho, e baixos níveis de engajamento e satisfação no trabalho (Salmela-Aro\&Nurmi, 2007).

A autoestima também pode afetar o desempenho, uma vez que um indivíduo que se sente mais seguro e capaz em suas ações possui um melhor desempenho acadêmico (Polese,Bortoluzzi\& Antonelli,2019; Li et al, 2018). Acadêmicos que se sentem desmotivados e desinteressados (baixa autoestima) podem apresentar aprendizagem comprometida, obtendo um rendimento inferior (Alves, 2009; Polese et al., 2019), fator que pode ocasionar os sintomas da Síndrome de Burnout.

Cabe destacar um fator limitante de 'causa x efeito' em relação à autoestima apontada na literatura. Há pesquisas que adotam o posicionamento da autoestima ser preditora (Johnson et al, 2020; Leroy-Frémont; Desrumaux\&Moundjiegout, 2014; Kang; Twigg\&Hertzman, 2010). Todavia,também há pesquisas que adotam o resultado na autoestima ser o efeito (Enache, 2013). Adotou-se nesta pesquisa a primeira perspectiva.

Além da autoestima, evidências apontam que a demanda de trabalho pode resultar no desencadeamento de sintomas (Jodas\& Haddad, 2009; Moreira, Brito, Obregon, Ribas \&Lopes, 2017). Jodas e Haddad (2009) destacam que atividades que demandam mais tempo do que o indivíduo tem disponível tornam-se um facilitador para o desenvolvimento da Síndrome de Burnout. Moreira, et al.(2017) destacam que profissionais na área da educação e suas relações com o trabalho também podem se tornar um desencadeador da síndrome,causada pela disparidade entre o esperado e o realizado no ambiente da pós-graduação. Tais questões podem estar vinculadas à relação com o orientador, visto que esses são os norteadores das atividades dos pós-graduandos.

Tem-se ainda que a exigência direcionada a alunos de pós-graduação, especificamente à stricto sensu, pode ser um estressor para o indivíduo. É necessário desenvolver o papel de pesquisador, dedicar-se à produtividade acadêmica de forma exclusiva, suas publicações devem ser realizadas em revistas de alto nível e, muitasvezes, não contam com apoio financeiro. No momento em que não alcança as expectativas estabelecidas, é comum o indivíduo frustrar-se, sentindo-se exausto mental e emocionalmente (Voltarelli, 2002).

$O$ estudo da síndrome em estudantes aponta que ela pode se desenvolver durante a vida acadêmica e perpetuar por toda a vida (Schaufeli, Salanova, González-Romá\&Bakker, 2002; Silva \& Vieira, 2015). E o fato de o indivíduo ser obrigado a conciliar diversas atividades na vida acadêmica, as dúvidas em relação ao futuro profissional, a necessidade de lidar com a pressão referente a prazos podem ser desencadeadores da síndrome (Duque, Brondani\& Luna, 2005; Souza,Trigueiro, Almeida \& Oliveira, 2010).

Com o crescimento da produção cientifica na área da Contabilidade, aumentou a oferta de cursos de pós-graduação stricto sensu, consequentemente houve aumentos na produção de artigos, teses, monografias e dissertações (Leite Filho \& Martins, 2006). Diante desta situação, "[...] muitos professores desses cursos, espontaneamente ou forçosamente, agregaram às suas funções docentes o papel de orientadores de trabalhos acadêmicos" (Martins, 2009; Leite Filho \& Martins, 2006). 
A orientação de alunos de pós-graduação é uma atividade delicada (Brown \& Adkins, 1998; Silva \& Vieira, 2015), pois vai além do auxílio na busca por um tema, está ligada a pesquisa, produtividade, encontros para que dúvidas sejam esclarecidas, relação de respeito e admiração. A qualidade do relacionamento aluno-orientador é entendida como um dos principais aspectos relacionados à conclusão do curso (Blanchard \&Haccoun, 2019). O conhecimento no desenvolvimento de uma dissertação ou tese é um processo construído por meioda relação mútua entre orientador e orientando (Machado, 2002). O orientador designado precisa ser competente para auxiliar os alunos na pesquisa, direcionando-os a novos conhecimentos e ajudando-os a se desenvolverem de forma pessoal e intelectual (Silva \& Vieira, 2015).

\subsection{Formulação de hipóteses}

Primeiramente, acredita-se que uma baixa autoestima pode influenciar negativamente nos fatores da Síndrome de Burnout. A autoestima é uma avaliação que o indivíduo faz de si mesmo e das relações sociais nas quais se envolve, podendo ser positiva ou negativa diante de determinados comportamentos (Rosenberg, 1965; Sedikides; Rudich; Gregg; Kumashiro\&Rusbult, 2004; Wagner, Lüdtke; Jonkmann\&Trautwein, 2013), em que se pode apresentar graus mais altos ou mais baixos (Silva \& Vieira, 2015). Assim, pode englobar questões de satisfação pessoal, autodepreciação, autovalorização, sentimento de fracasso, entre outras (Avanci, Assis, Santos \& Oliveira, 2007; Poleseet al., 2019).

A autoestima não é considerada estável, pois sofre altos e baixos no decorrer da vida e das experiências do indivíduo (Mosquera\&Stobäus, 2006; Poleseet al., 2019). Ela pode ser observada em pelo menos três níveis, baixo, médio e alto. O baixo - caracterizado por sentimentos de incapacidade, desajuste e falta de motivação diante de desafios por parte do indivíduo; o médio - o comportamento do indivíduo é inconsistente, oscila entre a adequação e inadequação à vida; e o alto - em que o indivíduo se sente competente e confiante (Poleseet al., 2019; Rosenberg, 1965).

Em 1965, Rosenberg desenvolveu um estudo voltado à autoestima, intitulado Society andtheAdolescent Self-Image, no qual era tratada a distribuição da autoestima em grupos e as influências que cada indivíduo sofria de acordo com o grupo em que estava inserido (Rosenberg, 1965). Neste mesmo estudo, foi desenvolvida a Rosenberg Self-Esteem Scale(RSES), sendo este um dos instrumentos mais utilizados para a avaliação da autoestima global (Romano, Negreiros \& Martins, 2007).

Diante das mudanças que ocorrem constantemente, é necessário que o indivíduo desenvolva autoestima suficiente para as adversidades a que todos estão sujeitos, sendo assim, ela será um fator decisivo para o sucesso ou o fracasso, pois a autoestima positiva é fundamental para a construção da confiança (Branden, 2001). Com isso, elaborou-se a primeira hipótese de pesquisa:

\section{H1: A alta A autoestima influencia negativamente nos sintomas da Síndrome de Burnout.}

Para uma melhor inferência dos resultados, foram separados os sintomas da Síndrome de Burnout, com isso tem-se que:

$\mathrm{H1}_{\mathrm{A}}$ : A alta autoestima influencia negativamente no sintoma de Baixa Eficácia.

$\mathrm{H1}_{\mathrm{B}}$ : A alta autoestima influencia negativamente no sintoma de Exaustão.

$\mathrm{H1}_{\mathrm{C}}$ : A alta autoestima influencia negativamente no sintoma de Descrença.

Assim, considera-se que a presença de autoestima mais elevada irá influenciar na presença de níveis mais baixos dos sintomas da Síndrome de Burnout, ao passo que a presença de autoestima baixa irá influenciar na presença de níveis mais elevados dos sintomas da Síndrome de Burnout.

Além da autoestima, estressores acadêmicos podem ser preditivos da Síndrome de Burnout (Hish et al., 2019). Outra causa que se acredita que pode influenciar nos fatores dessa síndrome é a relação do pós-graduando com o orientador, visto que na fase de pós-graduação o orientador torna-se um guia para o orientando (Silva \& Vieira, 2015). 
Contudo, em certos casos a orientação torna-se inadequada pelo fato de esquecerem ou ignorarem o número limite de estudantes que cada orientador pode conduzir, por este motivo, muitas vezes a orientação perde a intensidade e qualidade (Piccinin, 2003). Nesse sentido, Frame e Allen (2002) apontam que um fator de sucesso na relação orientador-orientando é a acessibilidade do orientador. O suporte fornecido pelo orientador de pesquisa é entendido como uma das chaves para o sucesso em estudos de nível superior (Blanchard \&Haccoun, 2019).

Relações disfuncionais do orientador, envolvendo questões que variam de frequência inadequada de orientações a maus-tratos, têm sido frequentemente associadas ao esgotamento dos alunos de doutorado (Hishet al., 2019). Ademais, estudos apontam ainda que o abandono das atividades na pós-graduação estaria ligado a problemas emocionais e ao sentimento de desamparo por parte dos orientandos (Carvalho, 1994; Luna, 1983; Sanches, 1992). Dado o exposto, acredita-se que a acessibilidade do orientador pode diminuir os fatores da Síndrome de Burnout. Elaborou-se, então,a segunda hipótese de pesquisa:

H2: A acessibilidade do orientador influencia negativamente sintomas da Síndrome de Burnout Assim como na hipótese 1, foram segregados os sintomas da Síndrome de Burnout, segregando a hipótese em:

$\mathrm{H}_{\mathrm{A}}$ : A acessibilidade do orientador influencia negativamente no sintoma de Baixa Eficácia.

$\mathrm{H}_{\mathrm{B}}$ : A acessibilidade do orientador influencia negativamente no sintoma de Exaustão.

$\mathrm{H}_{\mathrm{C}}$ : A acessibilidade do orientador influencia negativamente no sintoma de Descrença.

Desta forma, considera-se que a presença de níveis mais elevados de acessibilidade do orientador irá influenciar na presença de níveis mais baixos dos sintomas da Síndrome de Burnout, ao passo que a presença de níveis mais baixos de acessibilidade do orientador irá influenciar na presença de níveis mais elevados dos sintomas da Síndrome de Burnout.

Além da acessibilidade, Severino (2009) aponta que o trabalho realizado em conjunto deve ser enriquecedor e eficaz para ambas as partes, sem que o orientando fique abandonado e sem que o orientador abafe o orientando. Entre outros aspectos, a relação com o orientador ou supervisor é um dos aspectos que se relaciona com os sintomas de esgotamento (Janikova\&Buzgova, 2017; Turnipseed, 1994). Na visão do orientando, o orientador torna-se um guia (Silva \& Vieira, 2015). E, por ambas as partes, deve haver conscientização de que esta relação é profissional, na qual haverá compartilhamento de conhecimentos (Severino, 2009).

Severino (2009) ainda aponta que a orientação deveria ser um processo ausente de qualquer forma de opressão ou submissão, benéfica para ambas as partes, em que o crescimento fosse recíproco e houvesse o trabalho em conjunto. Kovach Clark, Murdock e Koetting (2009) demonstram que o forte apoio do orientador está negativamente relacionado ao esgotamento em estudantes matriculados em um programa de psicologia de aconselhamento.

Dado o exposto, espera-se que uma boa relação com o orientador possa influenciar negativamente nos fatores da Síndrome de Burnout. A partir disso, elaborou-se a hipótese de pesquisa:

H3: A boa relação com o orientador influencia negativamente nos sintomas da Síndrome de Burnout. Para a hipótese 3 também foram separados os sintomas, dividindo a hipótese em:

H3 ${ }_{\mathrm{A}}$ : A boa relação com o orientador influencia negativamente no sintoma de Baixa Eficácia.

$H 3_{B}$ : A boa relação com o orientador influencia negativamente no sintoma de Exaustão.

H3 ${ }_{\mathrm{C}}$ : A boa relação com o orientador influencia negativamente no sintoma de Descrença.

Assim, considera-se que a presença de níveis mais elevados de uma boa relação com o orientador irá influenciar na presença de níveis mais baixos dos sintomas da Síndrome de Burnout, ao passo que a presença de níveis mais baixos de uma boa relação com o orientador irá influenciar na presença de níveis mais elevados dos sintomas da Síndrome de Burnout. 
Com a definição das hipóteses a serem testadas, é apresentado o modelo teórico do estudo na Figura 1.

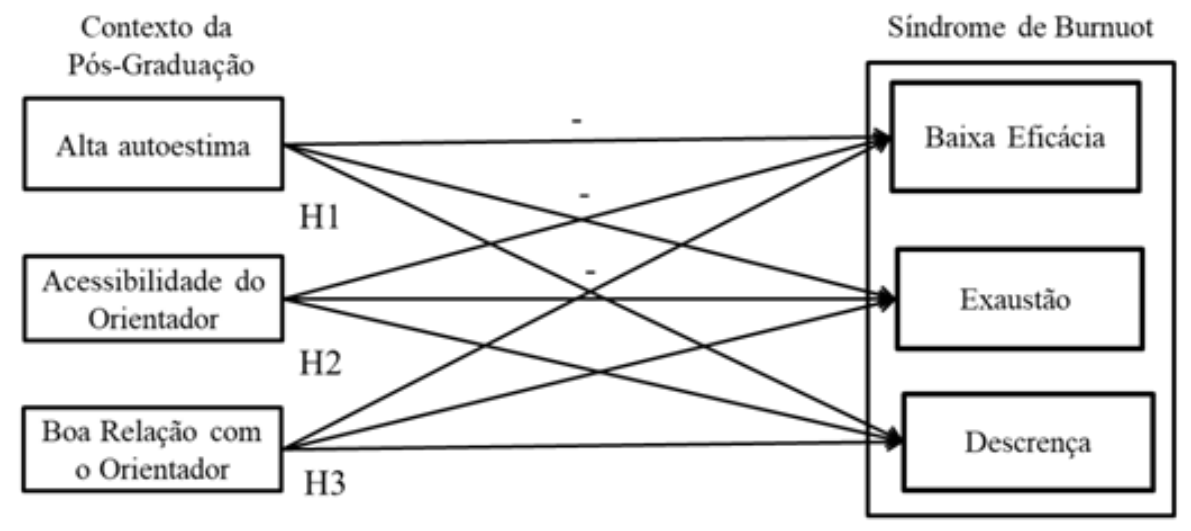

Figura 1. Modelo teórico

Apresentado o modelo teórico do estudo, partiu-se para os procedimentos metodológicos abordando a amostra estudada, o instrumento de pesquisa e as técnicas de análises utilizadas.

\section{Procedimentos Metodológicos}

O presente estudo se caracteriza como pesquisa descritiva, de natureza quantitativa, desenvolvida sob a forma de levantamento do tipo survey. Teve como objetivo analisar a influência da autoestima, acessibilidade e boa relação orientador-orientando na manifestação dos sintomas da Síndrome de Burnout em alunos de pós-graduação stricto sensu em Contabilidade no Brasil. A população do estudo é composta pelos acadêmicos (mestrandos e doutorandos) de pós-graduação stricto sensu na área de Ciências Contábeis.

O questionário eletrônico foi encaminhado para as 27 coordenações de programas de pós-graduação e solicitou-seque fosse repassado aos acadêmicos. Também foi encaminhado o questionário para os e-mails a que os pesquisadores tiveram acesso.O poder estatístico do tamanho da amostra foi calculado a partir das variáveis preditoras sobre a variáveis dependentes. O tamanho do efeito médio de 0,15 , o poder da amostra de $1-\beta=0,8$ e o nível de significância de $\alpha=0,05$ (Faul, Erdfelder, Buchner, \& Lang, 2009), utilizando o software $\mathrm{G}^{\star}$ Power. O período da coleta de dados foi entre os meses de outubro de 2018 a junho de 2019, obtendo-se 141 repostas válidas.

O questionário aplicado aos alunos foi dividido em quatro seções. A primeira seção era composta por questões socioeconômicas, que possuem o intuito de descrever o perfil dos respondentes. A segunda seção se refere ao questionário MBI-HSS para a análise da existência de traços da Síndrome de Burnout (Monte, 2005) a partir da adaptação de Peleias, Guimarães, Chan e Carlotto (2017). O instrumento é composto por 15 itens que se dividem nas três dimensões da síndrome: Eficácia - seis questões, Exaustão Emocional - cinco questões e Descrença - quatro questões. Após a coleta, as questões relativas à Eficácia tiveram seus valores invertidos, para representar 'Baixa Eficácia', alinhando com os demais construtos de sintomas da Síndrome de Burnout da Escala para fins de análise.

A terceira seção refere-se à análise da autoestima e foi utilizadaa Escala de autoestima de Rosenberg, traduzida de sua obra intitulada Society and the Adolescent Self-Image. O instrumento é composto por 10 questões (Rosenberg, 1965), sendo cinco relativas a "alta autoestima" e cinco relativas à 'Baixa autoestima'. Foi mensurada em escala Likert de 7 pontos, sendo pontuada1 para "discordo totalmente" e 7 para "concordo totalmente". Após a coleta, as questões relativas à 'Baixa autoestima' tiveram seus valores invertidos, bem como foi realizada a soma do total das questões, variando entre 10 e 70 pontos. Pontuações próximas de 10 representam baixa autoestima e pontuações próximas de 70 representam elevada autoestima. 
A quarta e última seção é referente à relação orientador-orientando, a partir das percepções de "acessibilidade do orientador" e "boa relação orientador-orientado". Para essas dimensões, foi utilizado o questionário desenvolvido por Silva e Vieira (2015). Todas as questões, com exceção da Escala de autoestima de Rosenberg, foram mensuradas em escala Likert de 7 pontos, sendo pontuadas1 - Nunca; 2 - Raras as vezes; 3 - Algumas vezes; 4 - Na metade do tempo, apenas; 5 - Em vários momentos; 6 - Quase sempre; 7 - Sempre.

Após a coleta dos questionários, foi realizada a estatística descritiva dos respondentes da pesquisa e das assertivas do estudo. Em seguida, foi realizado o teste de hipóteses do estudo a partir da técnica de Modelagem de Equações Estruturais (Structural Equations Modeling), realizada pelos mínimos quadrados parciais, com a utilização do software Smart PLS 3.Antes da realização da Modelagem de Equações Estruturais, foi realizada a avaliação da validade e confiabilidade do modelo de mensuração, conforme Hair Jr et al. (2014), por meio da análise da: Variância Média Extraída (AVE) e consistência interna, por meio do Alfa de Cronbach (AC) e Confiabilidade Composta (CC) (Hair Jr, Hult, Ringle\&Sarstedt, 2016; Ringle, Silva \&Bido, 2014).

A Modelagem de Equações Estruturais envolve a avaliação simultânea de múltiplas variáveis e seus relacionamentos (Hair Jr et al., 2016; Ringle et al., 2014). São calculadas as correlações entre os construtos e suas variáveis mensuradas e em seguida são realizadas regressões lineares simultaneamente entre os construtos (Hair Jr et al., 2016; Ringle et al., 2014). Para o teste de hipóteses e análise da significância das relações (p-valor) entre as variáveis no modelo estrutural, utilizou-se o procedimento de Boot straping (Hair Jr et al., 2016; Ringle et al., 2014).

\section{Apresentação e Análise dos Resultados}

\subsection{Caracterização dos respondentes}

Primeiramente, o estudo traçou um perfil dos respondentes da pesquisa. Dos 144 questionários respondidos, 3 foram desconsiderados por não terem sido respondidos em sua totalidade. Sendo assim, compõem a amostra final da pesquisa 141 respondentes. Destes pesquisados, a maioria é do sexo feminino (57,4\%), a faixa etária prevalecente é dos 20 aos 29 anos (51,77\%), sendo que as idades predominantes são 24 e 25 anos. Isto indica um lapso pequeno entre a graduação e a pós-graduação. Dos 141 acadêmicos, $51,8 \%$ não possuem união estável e $79,4 \%$ não possuem filhos. A maioria dos estudantes é de instituição pública $(94,3 \%)$ e $60,3 \%$ são alunos de mestrado.

Para a escolha da instituição de ensino, obteve-se um a maior relevância é a cidade em que a instituição está situada (52,5\%) e seguidamente o fato de ser pública (48,9\%). Ambos são importantes para os acadêmicos, pois os custos da pós-graduação não são baratos e podem tornar-se mais onerosos caso o estudante precise mudar de cidade. A instituição ser reconhecida apresentou relevância de 43,3\%, enquanto o nome e a tradição tiveram menor relevância, totalizando $22 \%$.

\subsection{Estatística Descritiva}

Após a caracterização dos respondentes, o estudo buscou medir a percepção dos pós-graduandos sobre: autoestima, acessibilidade e relacionamento com o orientador e o nível de exposição dos alunos à Síndrome de Burnout nas três dimensões. A Tabela 2 apresenta a estatística descritiva referente a autoestima, acessibilidade e relacionamento com o orientador. 
Tabela 2

\section{Estatística descritiva da Autoestimaautoestima}

\begin{tabular}{|c|c|c|c|c|c|c|c|}
\hline \multicolumn{8}{|c|}{ Frequência da Respostas } \\
\hline \multicolumn{8}{|c|}{ Autoestima } \\
\hline & 1 & 2 & 3 & 4 & 5 & 6 & 7 \\
\hline AUT5 - No geral, estou satisfeito comigo mesmo. & $4,96 \%$ & $4,96 \%$ & $9,22 \%$ & $23,40 \%$ & $13,48 \%$ & $31,91 \%$ & $12,06 \%$ \\
\hline AUT6 - Às vezes, eu acho que não sou bom em tudo. & $4,26 \%$ & $6,38 \%$ & $18,44 \%$ & $8,51 \%$ & $27,66 \%$ & $16,31 \%$ & $18,44 \%$ \\
\hline $\begin{array}{l}\text { AUT1 - Eu sinto que eu tenho um bom número de } \\
\text { qualidades. }\end{array}$ & $0,00 \%$ & $5,67 \%$ & $12,06 \%$ & $12,06 \%$ & $34,75 \%$ & $21,99 \%$ & $13,48 \%$ \\
\hline $\begin{array}{l}\text { AUT2 - Eu sou capaz de fazer as coisas, assim como a } \\
\text { maioria das outras pessoas. }\end{array}$ & $0,00 \%$ & $2,13 \%$ & $12,77 \%$ & $10,64 \%$ & $22,70 \%$ & $32,62 \%$ & $19,15 \%$ \\
\hline $\begin{array}{l}\text { AUT7 - Eu sinto que não tenho muito do que me } \\
\text { orgulhar. }\end{array}$ & $19,15 \%$ & $30,50 \%$ & $23,40 \%$ & $7,80 \%$ & $9,93 \%$ & $7,09 \%$ & $2,13 \%$ \\
\hline AUT8 - Eu certamente me sinto inútil às vezes. & $26,24 \%$ & $21,28 \%$ & $8,51 \%$ & $25,53 \%$ & $6,38 \%$ & $9,93 \%$ & $2,13 \%$ \\
\hline $\begin{array}{l}\text { AUT3 - Eu sinto que eu sou uma pessoa de valor, pelo } \\
\text { menos em um plano igual com os outros. }\end{array}$ & $0,00 \%$ & $1,42 \%$ & $12,77 \%$ & $12,06 \%$ & $24,82 \%$ & $27,66 \%$ & $21,28 \%$ \\
\hline $\begin{array}{l}\text { AUT9 - Eu gostaria de poder ter mais respeito por } \\
\text { mim mesmo. }\end{array}$ & $12,06 \%$ & $25,53 \%$ & $17,73 \%$ & $9,22 \%$ & $10,64 \%$ & $9,93 \%$ & $14,89 \%$ \\
\hline $\begin{array}{l}\text { AUT10 - No geral, estou inclinado a sentir que sou } \\
\text { um fracasso. }\end{array}$ & $41,84 \%$ & $25,53 \%$ & $15,60 \%$ & $4,26 \%$ & $6,38 \%$ & $3,55 \%$ & $2,84 \%$ \\
\hline AUT4 - Eu tomo uma atitude positiva em relação a mim. & $0,00 \%$ & $4,26 \%$ & $18,44 \%$ & $9,22 \%$ & $24,11 \%$ & $26,24 \%$ & $17,73 \%$ \\
\hline
\end{tabular}

Para a dimensão de autoestima, que visava captar a avaliação que os indivíduos fazem de si mesmos, destaca-se uma frequência alta para a concordância com as assertivas apresentadas, tem-se com essas que os pós-graduandos se sentem competentes e confiantes, com destaque na crença do seu valor como pessoa e na capacidade de realizar as atividades que precisam. Ressalta-se a importância dessa elevada autoestima dos respondentes que pode auxiliar na superação das dificuldades impostas pela pós-graduação stricto sensu. Notou-se ainda o maior desvio na assertiva de atitudes positivas quanto a si mesmo, o que pode atrapalhar a manutenção dessa autoestima, visto que ela não é estável e sofre oscilações no decorrer das experiências, como aponta Polese et al., (2019).

Partindo para a análise referente às percepções dos pós-graduandos sobre sua orientação, apresentados na Tabela 3, na dimensão de acessibilidade do orientador, a frequência das respostas aponta que a maioria dos alunos tem uma boa percepção da acessibilidade por parte dos orientadores. Fato evidenciado ainda pelas assertivas ACE1 e ACE4. Todavia, em relação aos prazos dos feedbacks, tem se uma queda nas respostas mais positivas, indicando um possível ponto de melhoria para parte dos orientadores. Assim como na dimensão de acessibilidade do orientador, para a boa relação com orientador, destinada a captar o bom relacionamento, respeito, admiração e contribuição dos orientadores de pósgraduação stricto sensu em Contabilidade, de uma forma geral, apresenta uma frequência alta para as respostas positivas as assertivas. Demonstrando sentimentos positivos na percepção de boa parte dos pósgraduandos da sua relação com seus respectivos orientadores. 
Tabela 3

Estatística descritiva de acessibilidade e boa relação com o orientador

\begin{tabular}{|c|c|c|c|c|c|c|c|}
\hline \multicolumn{8}{|c|}{ Frequência da Respostas } \\
\hline \multicolumn{8}{|c|}{ Acessibilidade ao orientador } \\
\hline $\begin{array}{l}\text { ACE1 - Meu orientador sempre me atende quando } \\
\text { necessito. }\end{array}$ & $0,71 \%$ & $2,84 \%$ & $12,06 \%$ & $7,09 \%$ & $14,18 \%$ & $25,53 \%$ & $37,59 \%$ \\
\hline $\begin{array}{l}\text { ACE2 - Meu orientador se mostra preocupado } \\
\text { com meu desempenho no curso. }\end{array}$ & $4,26 \%$ & $12,77 \%$ & $14,89 \%$ & $7,09 \%$ & $11,35 \%$ & $24,11 \%$ & $25,53 \%$ \\
\hline $\begin{array}{l}\text { ACE3 - Meu orientador retorna rapidamente as } \\
\text { demandas que encaminho. }\end{array}$ & $2,13 \%$ & $7,09 \%$ & $14,18 \%$ & $7,09 \%$ & $20,57 \%$ & $21,28 \%$ & $27,66 \%$ \\
\hline ACE4 - Tenho fácil acesso a meu orientador. & $0,00 \%$ & $3,55 \%$ & $7,09 \%$ & $5,67 \%$ & $14,89 \%$ & $19,15 \%$ & $49,65 \%$ \\
\hline $\begin{array}{l}\text { ACE5 - Meu orientador concede feedback dos } \\
\text { meus trabalhos nos prazos estabelecidos. }\end{array}$ & $4,26 \%$ & $9,22 \%$ & $7,80 \%$ & $5,67 \%$ & $12,77 \%$ & $23,40 \%$ & $36,88 \%$ \\
\hline \multicolumn{8}{|c|}{ Boa relação com o orientador } \\
\hline $\begin{array}{l}\text { REL1 - Tenho um bom relacionamento com meu } \\
\text { orientador. }\end{array}$ & $0,71 \%$ & $1,42 \%$ & $5,67 \%$ & $6,38 \%$ & $11,35 \%$ & $11,35 \%$ & $63,12 \%$ \\
\hline REL2 - Meu orientador me trata com respeito. & $0,00 \%$ & $0,71 \%$ & $2,13 \%$ & $2,84 \%$ & $4,26 \%$ & $15,60 \%$ & $74,47 \%$ \\
\hline $\begin{array}{l}\text { REL3 - Considero meu orientador um bom } \\
\text { pesquisador. }\end{array}$ & $0,71 \%$ & $2,13 \%$ & $4,96 \%$ & $8,51 \%$ & $13,48 \%$ & $16,31 \%$ & $53,90 \%$ \\
\hline $\begin{array}{l}\text { REL4 - Meu orientador relaciona-se } \\
\text { adequadamente com seus orientandos. }\end{array}$ & $0,00 \%$ & $2,84 \%$ & $3,55 \%$ & $8,51 \%$ & $10,64 \%$ & $21,99 \%$ & $52,48 \%$ \\
\hline $\begin{array}{l}\text { REL5 - Quando construir minha carreira terei } \\
\text { sempre meu orientador como "modelo". }\end{array}$ & $6,38 \%$ & $8,51 \%$ & $7,09 \%$ & $9,22 \%$ & $19,15 \%$ & $17,02 \%$ & $32,62 \%$ \\
\hline $\begin{array}{l}\text { REL6 - Meu orientador contribui com ideias para } \\
\text { meus trabalhos. }\end{array}$ & $2,84 \%$ & $9,22 \%$ & $8,51 \%$ & $8,51 \%$ & $13,48 \%$ & $23,40 \%$ & $34,04 \%$ \\
\hline $\begin{array}{l}\text { REL7 - Meu orientador direciona adequadamente } \\
\text { minhas pesquisas. }\end{array}$ & $4,26 \%$ & $8,51 \%$ & $7,80 \%$ & $11,35 \%$ & $13,48 \%$ & $19,15 \%$ & $35,46 \%$ \\
\hline $\begin{array}{l}\text { REL8 - Meu orientador domina os temas de } \\
\text { minhas pesquisas. }\end{array}$ & $2,84 \%$ & $6,38 \%$ & $12,06 \%$ & $8,51 \%$ & $16,31 \%$ & $23,40 \%$ & $30,50 \%$ \\
\hline $\begin{array}{l}\text { REL9 - Meu orientador reconhece minhas } \\
\text { conquistas. }\end{array}$ & $3,55 \%$ & $12,06 \%$ & $6,38 \%$ & $4,26 \%$ & $12,77 \%$ & $26,24 \%$ & $34,75 \%$ \\
\hline $\begin{array}{l}\text { REL10 - Meu orientador desempenha o papel de } \\
\text { orientador com excelência. }\end{array}$ & $4,26 \%$ & $4,26 \%$ & $8,51 \%$ & $8,51 \%$ & $13,48 \%$ & $23,40 \%$ & $37,59 \%$ \\
\hline REL11 - Tenho admiração por meu orientador. & $1,42 \%$ & $6,38 \%$ & $9,93 \%$ & $7,09 \%$ & $9,22 \%$ & $15,60 \%$ & $50,35 \%$ \\
\hline
\end{tabular}

Entre as assertivas, destaca-se a frequência da REL2, apresentando que na absoluta maioria das relações orientador-orientando há uma percepção de respeito no tratamento apresentado pelo orientador no entendimento dos pós-graduandos. Além do respeito, destacam-se o bom relacionamento e a admiração apresentados, parte importante, visto que o orientador é um guia na realização da pósgraduação, como aponta Severino (2009). Ressalta-se a diferença de frequência para a assertiva relacionada ao direcionamento das pesquisas. Com isso, apesar do bom relacionamento, para parte dos respondentes há a percepção de que ainda faltam contribuições ideias na realização das pesquisas.

Para a autoestima, e nas dimensões vinculadas à relação com o orientador, destaca-se ainda a frequência de respostas baixas, principalmente no desempenho do papel do orientador na percepção dos pós-graduandos, fato negativo já apontado por outros estudos (Kovach et al., 2009; Janikova\&Buzgova, 2017) que examinam o contexto da pós-graduação. Após a análise das percepções de autoestima e as assertivas referentes ao relacionamento com o orientador, buscou-se a estatística descritiva referente à Síndrome de Burnout. Os resultados são apresentados na Tabela 4. 
Tabela 4

Estatística descritiva da Síndrome de Burnout para os acadêmicos de mestrado e doutorado em Contabilidade

\begin{tabular}{|c|c|c|c|c|c|c|c|}
\hline \multicolumn{8}{|c|}{ Frequência da Respostas } \\
\hline & 1 & 2 & 3 & 4 & 5 & 6 & 7 \\
\hline \multicolumn{8}{|c|}{ Eficácia } \\
\hline $\begin{array}{l}\text { EFI } 1 \text { - Posso resolver os problemas que } \\
\text { surgem nos meus estudos e pesquisas. }\end{array}$ & $0,00 \%$ & $2,13 \%$ & $12,77 \%$ & $10,64 \%$ & $19,86 \%$ & $39,72 \%$ & $14,89 \%$ \\
\hline $\begin{array}{l}\text { EFI } 2 \text { - Durante as aulas, sinto-me confiante, } \\
\text { realizo as tarefas de forma eficaz. }\end{array}$ & $2,13 \%$ & $2,13 \%$ & $6,38 \%$ & $15,60 \%$ & $5,67 \%$ & $50,35 \%$ & $17,73 \%$ \\
\hline EFI 3 - Considero-me um bom estudante. & $0,00 \%$ & $2,84 \%$ & $7,09 \%$ & $10,64 \%$ & $26,95 \%$ & $37,59 \%$ & $14,89 \%$ \\
\hline $\begin{array}{l}\text { EFI } 4 \text { - Sinto-me estimulado quando concluo } \\
\text { com êxito a minha meta de estudos e } \\
\text { pesquisas. }\end{array}$ & $0,00 \%$ & $4,26 \%$ & $5,67 \%$ & $7,09 \%$ & $14,18 \%$ & $30,50 \%$ & $38,30 \%$ \\
\hline $\begin{array}{l}\text { EFI } 5 \text { - Acredito que eu seja eficaz na } \\
\text { contribuição das aulas que frequento. }\end{array}$ & $0,00 \%$ & $4,96 \%$ & $14,18 \%$ & $9,22 \%$ & $31,91 \%$ & $28,37 \%$ & $11,35 \%$ \\
\hline \multicolumn{8}{|c|}{ Exaustão } \\
\hline $\begin{array}{l}\text { EXA } 1 \text { - Sinto-me consumido pelos meus } \\
\text { estudos e pesquisas. }\end{array}$ & $1,42 \%$ & $1,42 \%$ & $2,84 \%$ & $13,48 \%$ & $3,55 \%$ & $38,30 \%$ & $39,01 \%$ \\
\hline $\begin{array}{l}\text { EXA } 2 \text { - Sinto-me emocionalmente esgotado } \\
\text { pelos meus estudos e pesquisas. }\end{array}$ & $1,42 \%$ & $5,67 \%$ & $9,93 \%$ & $9,93 \%$ & $7,80 \%$ & $39,72 \%$ & $25,53 \%$ \\
\hline $\begin{array}{l}\text { EXA } 3 \text { - Sinto-me esgotado no fim de um dia } \\
\text { em que tenho aula. }\end{array}$ & $2,13 \%$ & $0,00 \%$ & $9,93 \%$ & $20,57 \%$ & $14,18 \%$ & $25,53 \%$ & $27,66 \%$ \\
\hline $\begin{array}{l}\text { EXA } 4 \text { - Sinto-me cansado quando me } \\
\text { levanto para enfrentar outro dia de aula. }\end{array}$ & $5,67 \%$ & $2,84 \%$ & $10,64 \%$ & $21,28 \%$ & $8,51 \%$ & $27,66 \%$ & $23,40 \%$ \\
\hline $\begin{array}{l}\text { EXA } 5 \text { - Estudar e frequentar as aulas são } \\
\text { para mim um grande esforço. }\end{array}$ & $14,18 \%$ & $7,80 \%$ & $12,06 \%$ & $21,28 \%$ & $7,80 \%$ & $22,70 \%$ & $14,18 \%$ \\
\hline \multicolumn{8}{|c|}{ Descrença } \\
\hline $\begin{array}{l}\text { DES } 1 \text { - Tenho me tornado menos } \\
\text { interessado nos meus estudos e pesquisas. }\end{array}$ & $21,28 \%$ & $9,93 \%$ & $12,77 \%$ & $19,86 \%$ & $7,80 \%$ & $20,57 \%$ & $7,80 \%$ \\
\hline $\begin{array}{l}\text { DES } 2 \text { - Tenho me tornado menos } \\
\text { interessado nos estudos e pesquisas desde } \\
\text { que entrei nesta universidade. }\end{array}$ & $31,91 \%$ & $14,89 \%$ & $9,22 \%$ & $13,48 \%$ & $7,80 \%$ & $14,89 \%$ & $7,80 \%$ \\
\hline $\begin{array}{l}\text { DES } 3 \text { - Tenho estado mais descrente do } \\
\text { meu potencial e da utilidade dos meus } \\
\text { estudos e pesquisas. }\end{array}$ & $18,44 \%$ & $15,60 \%$ & $11,35 \%$ & $19,86 \%$ & $8,51 \%$ & $18,44 \%$ & $7,80 \%$ \\
\hline $\begin{array}{l}\text { DES } 4 \text { - Eu questiono o sentido e a } \\
\text { importância de meus estudos e pesquisas. }\end{array}$ & $10,64 \%$ & $7,80 \%$ & $13,48 \%$ & $14,89 \%$ & $11,35 \%$ & $20,57 \%$ & $21,28 \%$ \\
\hline
\end{tabular}

Quanto à eficácia, a dimensão que visa às perspectivas dos indivíduos no que se refere ao cumprimento dos objetivos, nota-se que em todas as assertivas a maioria da frequência é superior a cinco. Aponta-se com isso com os pós-graduandos, sua maioria, se sentem capazes etêm conseguido cumprir seus objetivos na pós-graduação. A partir das assertivas, é possível observar que grande parte dos alunos estão motivados e se sentem capazes de realizar suas atividades. Entre essas assertivas, destaca-se, pela sua maior frequência nas respostas seis e sete, que os alunos se sentem mais estimulados quando concluem com êxito suas metas acadêmicas. Todavia, apesar das maiores frequências apontarem para uma boa eficácia, nota-se um percentual de respostas baixo para a eficácia. Infere-se, com isso, que o sentimento de eficácia não é generalizado, e parte dos pós-graduandos não tem cumprido seus objetivos acadêmicos. 
No caso da dimensão de exaustão, a frequência das respostas aponta para um alto nível de pósgraduandos com indícios de exaustão. Com isso, tem-se que, apesar de estarem sendo eficazes em seus objetivos acadêmicos, uma expressiva parte dos pós-graduandos apresentam sintomas de fadiga e esgotamento devido às suas demandas acadêmicas. No mais, pelas frequências expostas, tem-se que esse esgotamento se deve mais à rotina de estudos e pesquisas do que às aulas.

Entre as assertivas de exaustão, destaca-se ainda que para a assertiva "Sinto-me consumido pelos meus estudos e pesquisas" $39 \%$ dos pós-graduandos respondentes da pesquisa apontaram que se sentem consumidos por suas atividades acadêmicas todos os dias e $38,3 \%$ se sentem consumidos algumas vezes por semana. Apesar desse sentimento de esgotamento, é possível observar uma frequência alta para "sempre" e "quase sempre" na assertiva EFI1, tem-se que, mesmo exaustos com os estudos e pesquisas, os acadêmicos se sentem motivados quando concluem as metas de estudos e pesquisas, sendo que $36,2 \%$ sempre se sentem motivados, $29,8 \%$ quase sempre e $14,2 \%$ em vários momentos se sentem estimulados.

Nas questões da dimensão de descrença, que busca se há uma atitude indiferente e distante em relação ao trabalho, as frequências para as respostas negativas apresentadas pelos pós-graduandos foram mais baixas que o normal. Com destaque para a assertiva DES2, que trata do desinteresse nos estudos e pesquisas por parte dos acadêmicos, sendo que 22,69\% apresentam-se desinteressados e 21,2\% em metade do tempo apresentam desinteresse. Ressalta-se também a assertiva sobre a descrença do potencial e da utilidade dos meus estudos, fator preocupante para a pós-graduação.

Destaca-se ainda a alta variabilidade das assertivas referentes à descrença, a partir da qual se infere que parte dos pós-graduandos tem se apresentado indiferente aos estudos e pesquisas, o potencial e utilidade de suas pesquisas, dados preocupantes que merecem atenção, dada a importância do contexto da pós-graduação em Contabilidade.

\subsection{Modelo de mensuração e teste de hipóteses}

Após a estatística descritiva, realizou-se a análise fatorial exploratória, visando às variáveis latentes inseridas posteriormente no modelo estrutural.Os construtos foram validados, com exceção da variável autoestima na qual foram somados os valores tal como a escala de autoestima de Rosenberg (1965), a partir dos critérios estabelecidos por Fávero e Belfiore (2017) e Hair Jr. et al. 2016: (i) método de extração da análise de componentes principais, por rotação Varimax com normalização de Kaiser; (ii) análise de comunalidades; (iii) teste de adequação da amostra de Kaiser-Meyer-Olklin (KMO); e (iv) teste de esfericidade de Bartlett. Destaca-se que todos os construtos foram validados, não tendo nenhuma assertiva excluída.

Em seguida, a pesquisa partiu para a avaliação do modelo de mensuração, de acordo com as orientações de Hair Jr et al. (2016). Para isso, visou-se à confiabilidade e validade do modelo de mensuração, a partir dos índices de validade convergente (AVE), confiança na consistência interna (CC e AC) e validade discriminante realizada pelo critério de Fornell e Larcker (1981).

As validades convergentes são obtidas por meio das observações das Variâncias Médias Extraídas (Average Variance Extracted - AVEs), que avaliam o quanto as variáveis se correlacionam positivamente com os seus respectivos construtos. Para esse critério, Hair Jr et al. (2016) estabelecem que o valor esperado deve ser acima de 0,5 .

Foi observada a consistência interna, por meio do Alfa de Cronbach (AC), que é baseado em intercorrelações das variáveis e Confiabilidade Composta (CC), que prioriza as variáveis de acordo com as suas confiabilidades (Hair Jr. et al., 2014).Para a consistência interna, utilizou-se o Alfa de Cronbach (AC) e a Confiabilidade Composta (Ringle et al., 2014). Para esses critérios, Hair Jr. et al. (2014) indicam que valores acima de 0,7 são considerados adequados. 
Para a avaliação da validade discriminante, que visa analisar se as variáveis latentes são independentes uma das outras, foi utilizado o critério de Fornell e Larcker (1981), também conforme orientação de Hair Jr et al. (2016). Nela, compara-se as raízes quadradas dos valores das AVEs de cada construto com as correlações entre esses construtos, visto que as raízes quadradas das AVEs são maiores que as correlações entre os construtos (Fornell\&Larcker, 1981). Apesar de as variáveis Acessibilidade do Orientador e Boa Relação com o Orientador se mostrarem próximas, tem-se como variáveis independentes. A Tabela 5 apresenta a avaliação do modelo de mensuração.

Tabela 5

Validação do modelo de mensuração

\begin{tabular}{lcccccc}
\hline \multicolumn{1}{c}{ Variáveis } & Autoestima & AcessOrient & RelOrient & Eficácia & Exaustão & Descrença \\
\hline Autoestima & 1,000 & & & & & \\
\hline AcessOrient & 0,371 & 0,850 & & & & \\
\hline RelOrient & 0,310 & 0,817 & 0,833 & & & \\
\hline Eficácia & $-0,662$ & $-0,372$ & 0,258 & 0,747 & & \\
\hline Exaustão & $-0,546$ & $-0,203$ & $-0,243$ & $-0,309$ & 0,817 & 0,851 \\
\hline Descrença & $-0,662$ & $-0,399$ & $-0,381$ & 0,577 & 0,576 & 0,724 \\
\hline AVE & 1,000 & 0,722 & 0,694 & 0,588 & 0,667 & 0,913 \\
\hline CC & 1,000 & 0,928 & 0,961 & 0,883 & 0,909 & 0,872 \\
\hline AC & 1,000 & 0,903 & 0,955 & 0,842 & 0,875 & \\
\hline
\end{tabular}

Nota: AVE: Variâncias Médias Extraídas; CC: Confiabilidade Composta; AC: Alfa de Cronbach.

Verificou-se o $\mathrm{R}^{2}$ (Coeficiente de relação de Pearson) de cada construto, que indica o quanto cada variável dependente é explicada pelas variáveis independentes. Nos casos das pesquisas em Ciências Sociais, Cohen (1977) classifica o poder explicativo nas seguintes condições: $\mathrm{R}^{2}=2 \%$ : efeito pequeno, $\mathrm{R}^{2}=13 \%$ : efeito médio; e $\mathrm{R}^{2}=26 \%$ efeito grande. A partir do critério de Cohen (1977), tem-se o alto poder explicativo das variáveis de sintomas da Síndrome de Burnout que apresentaram o $\mathrm{R}^{2}$ de 0,401 para variável Baixa Eficácia, 0,311 para variável Exaustão e 0,471 para variável Descrença.

Para o teste de hipóteses, foi utilizado o procedimento de Boot straping, buscando-se a análise da significância das relações (p-valor) no modelo estrutural, por meio dos coeficientes de determinação de Pearson (Ringle et al., 2014). Na Tabela 6, apresentam-se os coeficientes de caminho, com base nos dados obtidos pelo Boot strapping.

Tabela 6

Coeficiente de caminhos e significância das relações

\begin{tabular}{cllrrr}
\hline \multirow{2}{*}{ Hipóteses } & \multicolumn{1}{c}{ Relação } & $\begin{array}{c}\text { Coeficiente } \\
\text { estrutural }\end{array}$ & $\begin{array}{c}\text { Erro } \\
\text { padrão }\end{array}$ & t-valor & p-valor \\
\hline \multirow{3}{*}{ H1 } & Autoestima ->Baixa Eficácia & $-0,545$ & 0,066 & 8,286 & 0,000 \\
\cline { 2 - 6 } & Autoestima -> Exaustão & $-0,541$ & 0,061 & 8,931 & 0,000 \\
\cline { 2 - 7 } & Autoestima -> Descrença & $-0,593$ & 0,057 & 10,317 & 0,000 \\
\hline \multirow{2}{*}{ H2 } & Acessibilidade do Orientador ->Baixa Eficácia & $-0,308$ & 0,131 & 2,352 & 0,019 \\
\cline { 2 - 7 } & Acessibilidade do Orientador -> Exaustão & $-0,161$ & 0,124 & 1,295 & 0,195 \\
\cline { 2 - 7 } & Acessibilidade do Orientador -> Descrença & $-0,072$ & 0,116 & 0,616 & 0,538 \\
\hline \multirow{2}{*}{ H3 } & Boa Relação com Orientador ->Baixa Eficácia & 0,169 & 0,125 & 1,353 & 0,176 \\
\cline { 2 - 7 } & Boa Relação com Orientador -> Exaustão & $-0,200$ & 0,121 & 1,649 & 0,099 \\
\cline { 2 - 7 } & Boa Relação com Orientador -> Descrença & $-0,131$ & 0,115 & 1,135 & 0,256 \\
\hline
\end{tabular}

Fonte: dados da pesquisa (2019). 
A partir do teste de hipótese, verificou-se, assim como prospectado pela Hipótese 1, uma relação negativa e significativa entre a autoestima e abaixa eficácia percebida pelos pós-graduandos. Com isso, infere-se que a avaliação que o indivíduo faz de si mesmo pode conduzir a uma melhor eficácia dos seus objetivos acadêmicos como pós-graduando, visto que um aumento da autoestima pode levar a uma menor percepção de baixa eficácia. $\mathrm{O}$ achado para os acadêmicos de pós-graduação em Contabilidade corrobora os resultados de Polese et al. (2019), de que os indivíduos que se sentem mais seguros possuem um melhor desempenho acadêmico.

Aponta-se, ainda, que a autoestima tem uma relação negativa e significante com a exaustão e a descrença dos indivíduos. Tem-se com o exposto que os indivíduos que se sentem competentes e confiantes apresentam menores sinais de Síndrome de Burnout, apresentando menos sentimentos de excesso de esforço, assim como cansaço extremo, fadiga, redução de energia e entusiasmo. Nota-se também para um coeficiente de relação maior entre autoestima e descrença do que com os sintomas de baixa eficácia e exaustão. Infere-se a importância da autoestima na condução das adversidades apresentadas pelas demandas da pós-graduação, principalmente no entusiasmo em relação às atividades a serem desempenhadas na formação acadêmica. Os resultados vão ao encontro do apresentado por Li et at (2018).

A hipótese 2, no entanto, foi parcialmente aceita, pois foi encontrada uma relação negativa e significante apenas entre a acessibilidade do orientador e o sintoma de baixa eficácia. Sugere-se a partir dos achados que o fácil acesso ao orientador influencia na percepção de uma maior eficácia, por parte dos pós-graduandos, mesmo não influenciando em uma menor exaustão ou descrença, no próprio potencial ou nos estudos realizados. Os achados vão de encontro com a literatura anterior, que indica que a de frequência inadequada de orientações podem estar associados à fadiga dos alunos de pós-graduação como aponta Hish et al.(2019). Dado que a acessibilidade também não afeta a descrença dos alunos quanto aos seus estudos, a falta de acessibilidade dos orientadores não tem sido um ponto principal na discussão da indiferença dos pós-graduandos.

Dessa forma, ao analisar a boa relação com o orientador e os sintomas da Síndrome de Burnout, tem-se a rejeição da Hipótese 3, visto que não foram encontradas relações significativas entre a boa relação com o orientador e os sintomas da Síndrome de Burnout. Contudo, aponta-se para uma relação negativa entre a boa relação com o orientador e a percepção de exaustão, a uma significância de $10 \%$. Com isso, entende-se que os pós-graduandos que apresentam uma relação saudável com seus orientadores, com sentimentos de respeito e admiração, podem se sentir menos exaustos em relação a seus estudos.

Infere-se, com parcimônia, a partir desse achado a importância dos orientadores e sua relação com os orientados para a conclusão dos estudos sem os sentimentos de fadiga e/ou esgotamento. O resultado corrobora com estudos anteriores que apontam para a importância do bom relacionamento orientadororientando na redução dos sintomas de esgotamento (Janikova\&Buzgova, 2017; Kovachet al., 2009).

Tem-se, com os achados do estudo, a autoestima como fator importante para evitar o estado de limite dos estudantes, de suas condições de desempenho físico e mental no período de pós-graduação. Apesar de estudos apontarem para a importância da acessibilidade e boa relação com o orientador, não foram encontradas relações significantes entre os itens, com exceção da acessibilidade no sintoma de baixa eficácia e boa relação com a exaustão. Aponta-se para a importância na conscientização de estudantes e orientadores no contexto da pós-graduação em Contabilidade de manter ambientes que estimulem um alto nível de autoestima e proporcionem um relacionamento saudável com seus orientadores, a fim de evitar distúrbios de caráter depressivo. 


\section{Considerações Finais}

A Síndrome de Burnout é um distúrbio de caráter depressivo e seu desenvolvimento é gradual e cumulativo. Um indivíduo acometido pela síndrome sente-se desmotivado e sem energia em resposta ao estresse. Para os estudantes de pós-graduação, em específico de stricto sensu, que precisam atuar como pesquisadores, com a necessidade de publicar em revistas de alto nível, exercer a docência de forma concomitante, desempenhar demais atividades, sejam elas voltadas à vida pessoal ou à pesquisa, tais situações podem ser desencadeadoras da Síndrome de Burnout. Desta forma, o objetivo desta pesquisa foi analisar a influência da autoestima e a relação orientador-orientando nos sintomas da Síndrome de Burnout em estudantes de pós-graduação stricto sensu em Contabilidade no Brasil.

A partir dos resultados da pesquisa, pode-se identificar que os pós-graduandos em Contabilidade apresentam níveis elevados de autoestima. Tem-se com as assertivas que esses se sentem competentes e confiantes. Assim, a avaliação que os indivíduos fazem de si mesmos não tem sido depreciada por estarem em um momento desafiador, tal como o curso de pós-graduação, como apontam estudos anteriores (Duque et al., 2005; Souza et al., 2010). No que tange à boa relação com o orientador, identificou-se, na maioria das assertivas, uma percentagem expressiva de assertivas demonstrando sentimentos positivos dos pós-graduandos. Além do respeito, destaca-se o bom relacionamento e a admiração apresentados, parte importante, visto que o orientador é um guia na realização da pós-graduação.

Sobre os aspectos da Síndrome de Burnout, o sintoma de exaustão apresentou uma percentagem de respondentes com sintomas da síndrome, todavia, na dimensão de baixa eficácia, uma percentagem pequena dos pós-graduandos apresentaram o sintoma. Infere-se a partir dos achados que os pósgraduandos se sentem capazes de realizar suas atividades e têm conseguido cumprir seus objetivos na pós-graduação, apesar de tais atividades estarem causando um excesso de fadiga nesses estudantes, o que foi indicado pela dimensão de exaustão. Além da exaustão causada pela pós-graduação, os achados apontam alta frequência de respondentes com sintoma na dimensão de descrença, evidenciando uma atitude indiferente e distante em relação ao trabalho. Depreende-se que parte dos pós-graduandos em Contabilidade tem-se apresentado indiferente e descrente quanto aos estudos, pesquisas, potencial e utilidade de suas pesquisas. Tal dado merece atenção, haja vista a importância do contexto da pósgraduação em contabilidade nacional.

No teste de hipótese, a análise apontou que a percepção de autoestima tem sinal negativo com os sintomas da Síndrome de Burnout. Com isso, infere-se que a avaliação que o indivíduo faz de si mesmo pode conduzir a uma melhor eficácia dos seus objetivos acadêmicos como pós-graduando. Tal aspecto permite deduzir, com parcimônia, a importância da autoestima na condução das adversidades apresentadas pelas demandas da pós-graduação. Sugere-se a partir do achado que os programas de pós-graduação busquem meios de desenvolver a autoestima nos pós-graduandos durante sua formação acadêmica por meio de incentivos e reconhecimento.

Todavia, não foram encontradas relações entre a acessibilidade do orientador ea boa relação com o orientador nos sintomas da Síndrome de Burnout. Identificou-se, porém, uma relação negativa e significante entre acessibilidade e baixa eficácia e boa relação com o orientador e a exaustão. Infere-se, com isso, que os pós-graduandos que veem os seus orientadores acessíveis e dispostos a contribuir se sentem mais eficazes em sua demanda. No mais, os que têm a percepção de uma relação saudável com seus orientadores, com sentimentos de respeito e admiração se sentem menos fadigados em relação a seus estudos. Tem-se, assim, que os orientadores possuem papel importante no percurso acadêmico de seus orientados, corroborando com estudos anteriores. 
O estudo traz como contribuição um panorama do contexto da pós-graduação em Contabilidade no Brasil, acerca da percepção dos acadêmicos sobre sua autoestima, acessibilidade e boa relação com o orientador e os sintomas da Síndrome de Burnout, tema com poucas evidências no contexto contábil estudado. Nesse sentido, o presente estudo chama a atenção para a importância dos acadêmicos manterem uma visão positiva de si mesmos e das relações sociais nas quais se envolvem no contexto da pósgraduação. Estudos têm apontado para o desenvolvimento gradativo de sintomas da Síndrome de Burnout nos estudantes (Hishet al., 2019; Schaufeli et al., 2002; Silva \& Vieira, 2015) que podem se perpetuar pela vida inteira. E apesar de não terem sido encontrados fortes evidências no contexto da pós-graduação em Contabilidade, algumas respostas apontam para os fatores de falta de eficácia, exaustão e descrença de alguns pós-graduandos.

Por fim, para trabalhos futuros, sugere-se a inclusão de novas variáveis preditoras nos sintomas de Síndrome de Burnout nos pós-graduandos em Contabilidade para uma melhor compreensão do tema em questão. Abordagens alternativas, como entrevistas e observação participante podem auxiliar no avanço do tema, além de buscar a visão dos orientadores sobre toda essa discussão. Ainda, recomenda-se identificar os sintomas da Síndrome de Burnout em estudantes em outras áreas de negócios correlatas à contabilidade, visto que as evidências ainda são escassas.

\section{Referências}

Alves, L. M. S. A. (2009). Intervenção psicopedagógica: autoestima e a dimensão afetiva entre professores e alunos. In Actas do X Congresso Internacional Galego-Português de Psicopedagogia (pp. 4486-4496).

Avanci, J. Q., Assis, S. G., Santos, N. C. D., \& Oliveira, R. V. (2007). Adaptação transcultural de escala de auto-estima para adolescentes. Psicologia: Reflexão e crítica, 20(3), 397-405.

Benevides-Pereira, A. M. T. B. (2002). Burnout: Quando O Trabalho Ameaça O Bem. Casa do psicólogo. São Paulo: Casa do Psicólogo.

Bispo, F.C. S.; Santos Junior, A. B. (2014) O docente do ensino superior: educador ou prestador de serviços?. XI Simpósio de Excelência em Gestão e Tecnologia.

Blanchard, C., \& Haccoun, R. R. (2019). Investigating the impact of advisor support on the perceptions of graduate students. Teaching in Higher Education, 1-18.

Branden, N.(2001) Auto-estima: Como Aprender a Gostar de Si Mesmo. 39a ed. Sao Paulo: Saraiva.

Brown, G.; Adkins, M. (1998) Effective Teaching in the Higher Education. London: Routledge.

Carlotto, M. S., \& Câmara, S. G. (2006). Características psicométricas do Maslach Burnout InventoryStudent Survey (MBI-SS) em estudantes universitários brasileiros. Psico-USF, 11(2), 167-73.

Codo, W. (2002) Educação, carinho e trabalho: Burnout, a síndrome da desistência do educador, que pode levar à falência da educação. Petrópolis: Vozes.

Cohen, J. (1977). Statistical power analysis for the behavioral sciences (revised ed.).

Cadez, S., Dimovski, V., \& Groff, M. Z. (2017). Research, teaching and performance evaluation in academia: the salience of quality. Studies in Higher Education, 42(8), 1455-1473.

Duque, J. C., Brondani, J. T., \& Luna, S. P. L. (2005). Estresse e pós-graduação em Medicina Veterinária. Revista Brasileira de Pós-Graduação, 2(3).

Ekstedt, M., \& Fagerberg, I. (2005). Lived experiences of the time preceding burnout. Journal of advanced nursing, 49(1), 59-67.

Enache, R. G. (2013). Burnout syndrome and work accidents. Procedia-Social and Behavioral Sciences, $78,170-174$. 
Faul, F., Erdfelder, E., Buchner, A., \& Lang, A. G. (2009). Statistical power analyses using G* Power 3.1: Tests for correlation and regression analyses. Behavior research methods, 41(4), 1149-1160.

Fávero, L. P., \& Belfiore, P. (2017). Manual de análise de dados: estatística e modelagem multivariada com Excel $^{\oplus}$, SPSS ${ }^{\circledast}$ e Stata ${ }^{\oplus}$. Elsevier Brasil.

Fornell, C., \& Larcker, D. F. (1981). Evaluating structural equation models with unobservable variables and measurement error. Journal of marketing research, 18(1), 39-50.

Franco, M., Longhi, S. M., \& Ramos, M. D. G. (2009). Universidade e pesquisa: espaços de produção do conhecimento. Pelotas: UFPel.

Fuente, G. A.C., San Luis, C., Lozano, L. M., Vargas, C., García, I., \& Emilia, I. (2014). Evidencia de validez factorial del Maslach Burnout Inventory y estudio de los niveles de burnout en profesionales sanitarios. Revista Latinoamericana de Psicología, 46(1), 44-52.

Hair Jr, J. F., Hult, G. T. M., Ringle, C., \& Sarstedt, M. (2016). A primer on partial least squares structural equation modeling (PLS-SEM). Sage Publications.

Hish, A. J., Nagy, G. A., Fang, C. M., Kelley, L., Nicchitta, C. V., Dzirasa, K., \& Rosenthal, M. Z. (2019). Applying the Stress Process Model to Stress-Burnout and Stress-Depression Relationships in Biomedical Doctoral Students: A Cross-Sectional Pilot Study. CBE-Life Sciences Education, 18(4), ar51.

Janikova, E., Buzgova, R. (2017). Supervision as one of the possibilities of preventing and influencing burnout syndrome in healthcare. Ceskoslovenska Psychologie, 61(4), 363-378.

Jodas, D. A., \& Haddad, M. D. C. L. (2009). Síndrome de Burnout em trabalhadores de enfermagem de um pronto socorro de hospital universitário. Acta paulista de enfermagem, 22(2), 192-197.

Johnson, A. R., Jayappa, R., James, M., Kulnu, A., Kovayil, R., \& Joseph, B. (2020). Do low self-esteem and high stress lead to burnout among health-care workers? Evidence from a tertiary hospital in Bangalore, India. Safety and Health at Work.

Kang, B., Twigg, N. W., \& Hertzman, J. (2010). An examination of social support and social identity factors and their relationship to certified chefs' burnout. International Journal of Hospitality Management, 29(1), 168-176.

Kovach Clark, H., Murdock, N. L., \& Koetting, K. (2009). Predicting Burnout and Career Choice Satisfaction in Counseling Psychology Graduate Students. The Counseling Psychologist, 37(4), 580-606.

Kupcewicz, E., \& Jóźwik, M. (2020). Association of burnout syndrome and global self-esteem among Polish nurses. Archives of Medical Science, 15(1).

Leite Filho, Geraldo Alemandro, \& Martins, Gilberto de Andrade. (2006). Relação orientador-orientando e suas influências na elaboração de teses e dissertações. Revista de Administração de Empresas, 46(spe), 99-109.

Leroy-Frémont, N., Desrumaux, P., \& Moundjiegout, T. (2014). Les effets des demandes au travail et de la justice organisationnelle sur l'épuisement professionnel: quels effets médiateurs du soutien social et de l'estime de soi?. Pratiques psychologiques, 20(4), 231-248.

Li, J., Han, X., Wang, W., Sun, G., \& Cheng, Z. (2018). How social support influences university students' academic achievement and emotional exhaustion: The mediating role of self-esteem. Learning and Individual Differences, 61, 120-126.

Lima, T. B.; Silva, A. B. (2018) Como os mestrandos aprendem? Significados e transformações em um programa de pós-graduação em administração. Revista Reunir, v. 8, n.1, p. 36-55, jan/abr.

López, N. V., Boluda, I. K., \& Sanden, E. P. (2012). Antecedentes y efectos del burnout-engagement del vendedor. Cuadernos de Economía y Dirección de la Empresa, 15(3), 154-167.

Machado, A. M. N. (2002) A Bussola do Escrever: Desafios e Estrategias na Orientacao de Teses e Dissertacoes. Florianopolis: UFSC; Sao Paulo: Cortez, 2002. p. 67 - 83. 
Mallmann, C. S., Palazzo, L. S., Carlotto, M. S., \& de Castro Aerts, D. R. G. (2009). Fatores associados à síndrome de burnout em funcionários públicos municipais. Psicologia: teoria e prática, 11(2), 69-82.

Martins, O. S. (2009). Mestres em ciências contábeis pelo Programa Multiinstitucional da UNB/UFPB/ UFPE/UFRN: uma análise a partir de suas percepções e avaliações. Dissertação (Mestrado, Programa Multiinstitucional e Inter-Regional em Ciências Contábeis) Universidade de Brasília, Universidade Federal da Paraíba e Universidade Federal do Rio Grande do Norte. João Pessoa, p. 126.

Masclet, G., \& Mineure, S. (1999). The relationship between the burnout and self esteem among prison wardens. L'Encephale, 25(5), 450-460.

Maslach, C. (1976) Burned-out. Human Behavior 5, 16-22.

Monte, P. R. G. (2005) El síndrome de quemarse por eltrabajo Burnout. Madrid: Ediciones Pirámide.

Moreira, D. L., Brito, L. C., Obregon, S. L., Ribas, F. T. T., \& Lopes, L. F. D. (2017). Síndrome de burnout: estudo com professores da rede pública da cidade de farroupilha no Rio Grande do Sul. Revista Gestão \& Conexões, 6(1), 40-63.

Mosquera, J. J. M., \& Stobäus, C. D. (2006). Auto-imagem, auto-estima e auto-realização: qualidade de vida na universidade. Psicologia, saúde \& doenças, 7(1), 83-88.

Peleias, I. R., Guimarães, E. R., Chan, B. L., \& Carlotto, M. S. (2017). A síndrome de Burnout em estudantes de ciências contábeis de IES Privadas: pesquisa na cidade de São Paulo. Revista de Educação e Pesquisa em Contabilidade, 11(1), 30-51.

Pimenta, S.G.; Anastasiou, L. G.C. (2002) Docência no Ensino Superior. São Paulo: Cortez, V.1.

Polese, A. G., Bortoluzzi, S. C., \& Antonelli, R. A. (2019). Relação entre as Variáveis Comportamentais e o Desempenho Acadêmico: Um Estudo com Acadêmicos de Administração e Ciências Contábeis. Revista Mineira de Contabilidade, 20(3), 6-19.

Ringle, C. M., Silva, D., \& Bido, D. D. S. (2014). Modelagem de equações estruturais com utilização do SmartPLS. Revista Brasileira de Marketing, 13(2), 56-73.

Romano, A., Negreiros, J., \& Martins, T. (2007). Contributos para a validação da escala de auto-estima de Rosenberg numa amostra de adolescentes da região interior norte do país. Psicologia, saúde \& doenças, 8(1), 109-116.

Rosenberg, M. (2015). Society and the adolescent self-image. Princeton university press.

Ruviaro, M. D. F. S., \& Bardagi, M. P. (2010). Síndrome de burnout e satisfação no trabalho em profissionais da área de enfermagem do interior do RS. Barbarói, 194-216.

Salmela-Aro, K., \& Nurmi, J. E. (2007). Self-esteem during university studies predicts career characteristics 10 years later. Journal of Vocational Behavior, 70(3), 463-477.

Schaufeli, W. B., Salanova, M., González-Romá, V., \& Bakker, A. B. (2002). The measurement of engagement and burnout: A two sample confirmatory factor analytic approach. Journal of Happiness studies, 3(1), 71-92.

Schuster, M.S.; Dias.V.; Battistella, L.F. (2015) Percepções de Saúde e a Síndrome de Burnout -Aplicabilidade da Mbi-Gs. Revista de Carreiras e Pessoas, v. 5, n. 3, p. 380-391.

Sedikides, C., Rudich, E. A., Gregg, A. P., Kumashiro, M., \& Rusbult, C. (2004). Are normal narcissists psychologically healthy?: Self-esteem matters. Journal of personality and social psychology, 87(3), 400.

Severino, A. J. (2009). Pós-graduação e pesquisa: o processo de produção e de sistematização do conhecimento. Revista Diálogo Educacional, 9(26), 13-27.

Silva, A. H., \& Vieira, K. M. (2015). Síndrome de burnout em estudantes de pós-graduação: análise da influência da autoestima e relação orientador-orientando. Revista Pretexto, 16(1), 52-68. 
Silva, S. C. P. S., Nunes, M. A. P., Santana, V. R., Reis, F. P., Machado Neto, J., \& Lima, S. O. (2015). A síndrome de burnout em profissionais da Rede de Atenção Primária à Saúde de Aracaju, Brasil. Ciência \& Saúde Coletiva, 20, 3011-3020.

Souza, R. S., Trigueiro, R. P. C., de Almeida, T. N. V., \& de Oliveira, J. A. (2010). A pós-graduação e a síndrome de burnout: estudo com alunos de mestrado em administração. Revista Pensamento Contemporâneo em Administração, 4(3), 12-21.

Turnipseed, D. L. (1994). An analysis of the influence of work environment variables and moderators on the burnout syndrome. Journal of Applied Social Psychology, 24(9), 782-800.

Trzesniewski, K. H., Donnellan, M. B., \& Robins, R. W. (2003). Stability of self-esteem across the life span. Journal of personality and social psychology, 84(1), 205.

Voltarelli, J. C. (2002). Estresse e produtividade acadêmica. Medicina (Ribeirao Preto. Online), 35(4), 451-454.

Wagner, J., Lüdtke, O., Jonkmann, K., \& Trautwein, U. (2013). Cherish yourself: Longitudinal patterns and conditions of self-esteem change in the transition to young adulthood. Journal of Personality and Social Psychology, 104(1), 148.

Zuluaga, P. A. M., \& Moreno, S. M. (2012). Relación entre síndrome de burnout, estrategias de afrontamiento y engagement. Psicología desde el Caribe, 29(1), 205-227. 